\title{
Is it worth preserving the uterus? unanticipated pathology in hysterectomy for pelvic organ prolapse (POP)
}

\author{
Deeksha Pandey, Pranadeep Reddy Inukollu*, Jyothi Shetty, \\ Shripad Hebbar, Muralidhar V. Pai, Pratap Kumar
}

Department of Obstetrics and Gynecology, Kasturba Medical College, Manipal, Karnataka, India

Received: 06 August 2018

Accepted: 01 September 2018

\section{*Correspondence:}

Dr. Pranadeep Reddy Inukollu,

E-mail: pranadeepreddyinukollu@gmail.com

Copyright: (C) the author(s), publisher and licensee Medip Academy. This is an open-access article distributed under the terms of the Creative Commons Attribution Non-Commercial License, which permits unrestricted non-commercial use, distribution, and reproduction in any medium, provided the original work is properly cited.

\begin{abstract}
Background: In recent years concept of uterine conservation has been increasing at the time of surgical management of pelvic organ prolapse (POP). This study was intended to assess the risk of premalignant and malignant uterine/endometrial, and cervical pathology at the time of hysterectomy-based POP procedures, to better understand the risks of uterine conservation in the surgical treatment of POP in Indian setup.

Methods: Patients who had undergone vaginal hysterectomy for POP in last five years were identified by medical record tracking using ICD-9 codes. Case records then were reviewed to collect patient characteristics and the final histopathological diagnosis of the hysterectomy specimen. Cases with premalignant or malignant uterine/endometrial or cervical pathology recognized prior to surgery were excluded.

Results: A total of 573 women who underwent vaginal hysterectomy and pelvic floor repair for the sole indication of POP were included. On analyzing the histopathological diagnosis of the specimen obtained during surgery in $57.1 \%$ of cases the findings were consistent with the changes seen in cases of POP. Only $5.9 \%$ of cases had cervical or endometrial pathologies who would have required treatment/follow up in future if the uterus was left in situ.

Conclusions: The risk of missing a malignant and premalignant cervical or uterine pathology in women presenting with uterine prolapse is low if appropriate preoperative workup has been done. Uterine preservation in surgical management of POP could be considered an option.
\end{abstract}

Keywords: Hysterectomy, Pelvic organ prolapse, Uterus

\section{INTRODUCTION}

In recent years concept of uterine conservation has been increasing at the time of surgical management of pelvic organ prolapse (POP) with the popularity of minimally invasive surgeries for pelvic reconstruction. ${ }^{1}$ Concerns being unnecessary sacrifice of uterus which is now being considered as an innocent organ in the etio-pathogenesis of POP. Moreover, conserving uterus has been proposed to decrease the risk of vault prolapse because of intact cervical ring of ligamentous supports. Conservation of cervix might also maintain the sexual gratification and thus may provide a better quality of life, after surgery. Studies have also shown that uterine-preserving surgery is associated with greater functional improvement in these cases. ${ }^{2}$ Although there are no randomized trials comparing uterine conservation with hysterectomy-based POP procedures, existing evidence cites comparable success rates of $79-100 \%$ for multiple uterine-sparing POP procedures. ${ }^{3}$ On the other hand as POP is the usually a disease of older age group, who are more at risk of malignant pathology, risk of leaving behind uterus and cervix which might be harboring a pre-malignant or 
malignant lesion has to be addressed carefully before we standardize the uterine-sparing POP procedures in our day to day practice. This study was intended to assess the risk of premalignant and malignant uterine/endometrial, and cervical pathology at the time of hysterectomy-based POP procedures, to better understand the risks of uterine conservation in the surgical treatment of POP in Indian setup.

\section{METHODS}

Present study involved all patients who underwent vaginal hysterectomy at a teaching hospital in Southern India, in a span of five years (from 1st Jan 2013 to 31st Dec 2017). The study was approved by institutional ethical review board. Sample size came to 573 after taking all the patients during the five-year study period who satisfied the inclusion criteria.

\section{Inclusion criteria}

- All the patients who underwent hysterectomy for POP were included in the study during the five-year study period.

\section{Exclusion criteria}

- Cases with premalignant or malignant uterine/endometrial or cervical pathology recognized prior to surgery were excluded.

\section{Methodology}

Patients were identified by medical record tracking using ICD-9 codes. Case records then were reviewed to collect patient characteristics and the final histo-pathological diagnosis of the hysterectomy specimen.

\section{Outcome measures}

To look for incidence of abnormal and unexpected pathologies in the hysterectomy specimens of POP and measures that could be taken to avoid/deal with such situations in clinical practice

\section{Statistical analysis}

All calculations were made using SPSS 21.0 IBM Statistics released. August 2012 (IBM Corporation 1, New Orchard Road, Armonk, New York, 10504-1722 U.S.). Descriptive analysis was used for all the calculations to obtain the final results.

\section{RESULTS}

During the study period of five years (January 2012 to December 2017), a total of 573 women underwent vaginal hysterectomy and pelvic floor repair for the sole indication of POP. All were included in the analysis. Patient Characteristics: Mean age of these women was $59.6+8.9$ years. Most of the women (77.6\%) were menopausal. Histological Correlation: On analyzing the histopathological diagnosis of the specimen obtained during surgery in $64.6 \%$ of cases the findings were consistent with the changes seen in cases of POP. These findings included atrophic endometrium, chronic cervicitis and/or decubitus ulcers. There was no other associated abnormality detected in these cases. While in rest (i.e. $42.8 \%$ cases) associated pathologies were encountered, which are tabulated in Table 1.

Table 1: Histopathological diagnosis of all specimen obtained after hysterectomy done for indication of POP without any preoperative associated clinical diagnosis.

\begin{tabular}{ll} 
Histopathological Diagnosis & Frequency $(\%), \mathbf{N}=573$ \\
Changes consistent with uterine prolapse & $327(57.0)$ \\
\hline Adenomyosis & $88(15.3)$ \\
\hline Leiomyoma & $125(21.8)$ \\
Endometrial/cervical polyp & $56(09.8)$ \\
Endometrial hyperplasia (simple) & $11(01.9)$ \\
Endometrial hyperplasia (complex) & $01(00.2)$ \\
Tuberculous endometritis & $01(00.2)$ \\
Cervical intraepithelial neoplasia 1 (CIN 1) & $10(01.7)$ \\
Cervical intraepithelial neoplasia 2 (CIN 2) & $02(00.3)$ \\
Cervical intraepithelial neoplasia 3 (CIN 3)/Carcinoma in situ (CIS) & $09(01.6)$
\end{tabular}

These included leiomyoma (21.8), adenomyosis (15.3), endometrial polyp (9.8), endometrial hyperplasia (2.1), tuberculous endometriosis $(0.2)$, cervical intraepithelial neoplasia 1 (CIN 1) (1.7), cervical intraepithelial neoplasia 2 (CIN 2) (0.3), cervical carcinoma in situ
(CIS) (1.6). There was a considerable overlap as many specimens were found to have more than one pathology. The details of cervical and endometrial lesions that would require treatment/follow up if left in situ have been tabulated separately (Table 2, Table 3). 
Table 2: Characterization of patients with cervical pathologies if left in situ would have progressed and/or required treatment in future.

\begin{tabular}{|c|c|c|c|c|c|}
\hline Histological & Age & Parity & Menopause & Comorbidities & Related Findings \\
\hline Diagnosis & (years) & & (years) & & \\
\hline \multirow[t]{2}{*}{ CIN3 } & 55 & P2L2 & 5 & Diabetes Mellitus & DPV 3 months \\
\hline & & & & & Pap smear: NILM \\
\hline CIN3 & 54 & P4L4 & 3 & None & Pap smear: NILM \\
\hline CIN3 & 61 & P10L10 & 10 & Hypertension & Pap smear: NILM \\
\hline \multirow[t]{2}{*}{ CIN3 } & 66 & P2L2 & 20 & None & Pap smear: CIN1 \\
\hline & & & & & Colposcopy: cervicitis \\
\hline CIN3 & 50 & P3L3 & 14 & None & Pap smear: NILM \\
\hline CIN3 & 75 & P5L5 & 30 & Hydro-uretero nephrosis & Pap smear: ASCUS \\
\hline CIN3 & 64 & P3L2 & 15 & Hypertension & Pap smear: NILM \\
\hline CIN3 & 55 & P1L1 & 6 & Hypertension & Pap smear: inadequate \\
\hline CIN3 & 60 & P4L4 & 12 & None & Pap smear: NILM \\
\hline CIN2 & 51 & P2L2 & 2 & None & Pap smear: CIN1 \\
\hline CIN2 & 60 & P3L3 & 10 & None & Pap smear: NILM \\
\hline
\end{tabular}

Table 3: Characterization of patients with Uterine (Endometrial) pathologies if left in situ would have progressed and/or required treatment in future.

\begin{tabular}{|c|c|c|c|c|c|}
\hline Histological & Age & Parity & Menopause & Comorbidities & Related Findings \\
\hline Diagnosis & (years) & & (years) & & \\
\hline Simple hyperplasia & 44 & P3L3 & Pre & Diabetes mellitus & DPV 6 months \\
\hline Simple hyperplasia & 52 & P2L1NND1 & 3 & None & None \\
\hline \multirow[t]{2}{*}{ Simple hyperplasia } & 55 & P4L4 & 5 & Asthma & None \\
\hline & & & & Obesity & \\
\hline Simple hyperplasia & 45 & P2L2 & Pre & None & $\begin{array}{l}\text { AUB with continuous } \\
\text { vaginal bleeding, TVS (ET)- } \\
11 \mathrm{~mm} \text { D and C: WNL }\end{array}$ \\
\hline Simple hyperplasia & 50 & P2L2 & 1.5 & Hypothyroidism & None \\
\hline Simple hyperplasia & 57 & P3L3 & 10 & None & None \\
\hline Simple hyperplasia & 61 & P4L3 & 15 & Hypertension & DPV 4 months \\
\hline Simple hyperplasia & 60 & P6L4 & 12 & None & None \\
\hline Simple hyperplasia & 59 & P2L2 & 5 & None & None \\
\hline \multirow[t]{2}{*}{ Simple with atypia } & 51 & P1L1 & Pre & Obesity & \multirow{2}{*}{$\begin{array}{l}\text { AUB, TVS (ET): } 8 \mathrm{~mm} \\
\text { Endocell (indication High } \\
\text { risk for Endometrial Cancer: } \\
\text { SEH }\end{array}$} \\
\hline & & & & Hypertension & \\
\hline \multirow[t]{3}{*}{ Complex hyperplasia } & 47 & $\begin{array}{l}\text { P2L3 } \\
\text { (Twins) }\end{array}$ & 2 & Obesity & DPV 2 months \\
\hline & & & & Diabetes & \\
\hline & & & & Hypertension & \\
\hline Tubercular endometriti & 67 & P4L4 & 15 & None & $\mathrm{ET}: 3.6 \mathrm{~mm}$ \\
\hline
\end{tabular}

Cervical Pathologies: In this cohort we had a total of 11 $(1.9 \%)$ patients who were diagnosed to have high grade intraepithelial lesions of cervix (CIN 2/3). None of them had adopted a regular cervical screening strategy as per the guidelines. However, all patient had undergone a Pap smear in out hospital on presentation prior to surgery. None of these Pap smears had revealed a high-grade lesion. However, three of these 11 had got a report of low-grade lesions (two LSIL and one ASCUS). Colposcopy was performed for the two having LSIL to rule out higher grade lesions. The patient with ASCUS was not followed up as she already had procedentia with bilateral hydrouretero-nephrosis and borderline renal parameter on evaluation of renal function tests (RFT). So hysterectomy was planned for her without wasting much time.

\section{Uterine/endometrial pathologies}

Thirteen women were found to have significant pathologies in their endometrium (simple endometrial hyperplasia without atypia: 10 and one each of simple 
endometrial hyperplasia with atypia, complex endometrial hyperplasia without atypia and tubercular Endometritis). Patient characteristics and clinical presentation have been tabulated in Table 3 .

\section{DISCUSSION}

In present study we found that around $42.8 \%$ of women who underwent concomitant hysterectomy as a part of POP management had associated pathologies in histopathological evaluation of the specimen. Most of these (90.3\%) were incidental findings without any symptoms or need of treatment/follow up. Only two (0.3\%) specimen showed evidence of CIN-2 while nine (1.6\%) had cervical carcinoma in situ. As far as significant endometrial pathology was concerned only one lady had evidence of simple endometrial hyperplasia with atypia and one with complex hyperplasia, one woman was found to have tuberculous endometritis

In a study from US at the time of minimally invasive sacrocolpopexy when concurrent hysterectomy was performed, less than a percent $(0.92 \%)$ had abnormal uterine pathologic findings. Among the cohort of 324 women they studied all abnormal pathological findings were premalignant and focal. No invasive carcinoma was identified. $^{4}$

In a retrospective study with an aim to assess the incidence of a malignant and/or premalignant gynecological pathological condition in women undergoing vaginal hysterectomy for POP, the prevalence of undetected endometrial hyperplasia was $2.7 \%$, while no case of endometrial cancer was detected. Only a single case of cervical cancer, one of CIN III $(0.3 \%)$, and 3 cases of CIN I $(0.9 \%)$ were diagnosed on pathological review of the specimen. ${ }^{5}$ Rate of unanticipated pathologic findings in uterine specimen in our cohort during hysterectomy-based POP procedures is similar or lesser to that in the previous studies.

Frick et al, in a retrospective analysis of 644 patients who underwent hysterectomy concomitant with reconstructive surgery, found a $2.6 \%$ risk of premalignant or malignant uterine disease. ${ }^{3}$ Likewise Ramm et al found a $2.9 \%$ rate of premalignant or malignant disease in a cohort of 708 women. ${ }^{6}$ Renganathan et al tried to find out the risk of missing a malignancy among women who underwent vaginal hysterectomy for repair of prolapse and found an incidence of endometrial cancer of $0.9 \% .^{7}$ Osanna YK Wan et al found $0.47 \%$ incidence of hitherto unsuspected uterine malignancy in their cohort of women who underwent hysterectomy for POP. They also found three other cases of uterine premalignant conditions and five cases of CIN in their series of 640 women over nine years. $^{8}$

In present study population nine specimens obtained following hysterectomy for POP (as a part of Ward Mayo's procedure) had cervical CIS lesion, which would have required treatment later on. Preoperative for all of these women Pap smear was obtained, though it was the first Pap smear for most of them in their life time. Only two cases who had low grade pre-invasive lesions detected in Pap smears were followed up with a colposcopy.

It might be because of low sensitivity of single Pap test. Point to be kept in mind is that like many Asian countries routine cervical cancer screening is still not popular in India. Still, in a set up where uterine conservation during POP management is a preferred choice for all these nine women conservative management (conization) and follow up would have been enough, as none of them had any evidence of invasive disease. This emphasizes the need of close follow up with routine cervical cancer screening, in cases where uterus has been preserved in the management of POP.

One postmenopausal lady (age 67 years) was detected to have tuberculous endometritis, however she was totally asymptomatic. She was evaluated and was not found to have any active tuberculous focus, so no further treatment was offered to her. Genital tuberculosis is rare in postmenopausal women and responsible for only approximately $1 \%$ of postmenopausal bleeding patients. ${ }^{9}$

While investigating attitudes toward hysterectomy in women seeking care for pelvic organ prolapse, the trend was a preference to retain uterus at the time of surgery in the absence of a substantial benefit to hysterectomy. ${ }^{10-12}$ This is also an important reason that we must discuss the options, efficacies, drawbacks and the need of follow up, with the surgical managements available for POP including the surgeries with uterine conservation to help women make informed decisions. ${ }^{13,14}$

\section{CONCLUSION}

The risk of missing a malignant and premalignant cervical or uterine pathology in women presenting with uterine prolapse is low if appropriate preoperative workup has been done. Uterine preservation in surgical management of POP could be considered an option.

Funding: No funding sources

Conflict of interest: None declared

Ethical approval: The study was approved by the Institutional Ethics Committee

\section{REFERENCES}

1. Farthmann J, Watermann D, Erbes T, Roth K, Nanovska P, Gitsch G, et al. Functional outcome after pelvic floor reconstructive surgery with or without concomitant hysterectomy. Arch Gynecol Obstet. 2015;291(3):573-7.

2. Costantini E, Porena M, Lazzeri M, Mearini L, Bini $\mathrm{V}$, Zucchi A. Changes in female sexual function after 
pelvic organ prolapse repair: role of hysterectomy. Int Urogynecol J. 2013;24(9):14817.

3. Frick AC, Walters MD, Larkin KS, Barber MD. Risk of unanticipated abnormal gynecologic pathology at the time of hysterectomy for uterovaginal prolapse. Am J Obstet Gynecol. 2010;202(5):507e1-4.

4. Andy UU, Nosti PA, Kane S, White D, Lowenstein L, Gutman RE, et al. Incidence of unanticipated uterine pathology at the time of minimally invasive abdominal sacrocolpopexy. J Minim Invasive Gynecol.2014;21(1):97-100.

5. Grigoriadis T, Valla A, Zacharakis D, Protopapas A, Athanasiou S. Vaginal hysterectomy for uterovaginal prolapse: what is the incidence of concurrent gynecological malignancy? Int Urogynecol J. 2015 ;26(3):421-5.

6. Ramm O, Gleason JL, Segal S, Antosh DD, Kenton KS. Utility of preoperative endometrial assessment in asymptomatic women undergoing hysterectomy for pelvic floor dysfunction. Int Urogynecol $\mathbf{J}$. 2012;23(7):913-7.

7. Renganathan A, Edwards R, Duckett JR. Uterus conserving prolapse surgery-what is the chance of missing a malignancy? Int Urogynecol J. 2010;21(7):819-21

8. Wan OY, Cheung RY, Chan SS, Chung TK. Risk of malignancy 173 in women who underwent hysterectomy for uterine prolapse. Aust N Z J Obstet Gynaecol. 2013;53(2):190-6.

9. Gungorduk K, Ulker V, Sahbaz A, Ark C, Tekirdag AI. Postmenopausal tuberculosis endometritis. Infect Dis Obstet Gynecol. 2007;2007:27028.
10. Frick AC, Barber MD, Paraiso MF, Ridgeway B, Jelovsek JE, Walters MD. Attitudes toward hysterectomy in women undergoing evaluation for uterovaginal prolapse. Female Pelvic Med Reconstr Surg. 2013;19(2):103-9.

11. Wong K, Jakus-Waldman S, Yazdany T. Patient beliefs regarding hysterectomy in women seeking surgery for pelvic organ prolapse: findings in a predominantly Hispanic population. Female Pelvic Med Reconstr Surg. 2014;20(5):267-71.

12. Korbly NB, Kassis NC, Good MM, Richardson ML, Book NM, Yip S, et al. Patient preferences for uterine preservation and hysterectomy in women with pelvic organ prolapse. Am J Obstet Gynecol. 2013;209(5):470 e 1-6.

13. 1American Urogynecologic Society Best Practice Statement: Evaluation and Counseling of Patients With Pelvic Organ Prolapse. Female Pelvic Med Reconstr Surg. 2017;23(5):281-7.

14. Pakbaz M, Rolfsman E, Lofgren M. Are women adequately informed before gynaecological surgery? BMC Womens Health. 2017;17(1):68.

Cite this article as: Pandey D, Inukollu PR, Shetty J, Hebbar S, Pai MV, Kumar P. Is it worth preserving the uterus? unanticipated pathology in hysterectomy for pelvic organ prolapse (POP). Int J Reprod Contracept Obstet Gynecol 2018;7:4145-9. 